\title{
Surface Rupturing and Buried Dynamic-Rupture Models Calibrated with Statistical Observations of Past Earthquakes
}

\author{
by Luis A. Dalguer, Hiroe Miyake, Steven M. Day, and Kojiro Irikura
}

\begin{abstract}
In the context of the slip-weakening friction model and simplified asperity models for stress state, we calibrate dynamic rupture models for buried and surface-rupturing earthquakes constrained with statistical observations of past earthquakes. These observations are the kinematic source models derived from source inversions of ground-motion and empirical source models of seismic moment and rupture area. The calibrated parameters are the stress-drop distribution on the fault and average stress drop. We develop a set of dynamic rupture models that consist of asperities and surrounding background areas. The distribution of dynamic stress drop outside the asperity is characterized by a fraction of the stress drop on the asperity. From this set of models, we identify dynamic fault models with defined stressdrop characteristics that satisfy the observations. The selected dynamic fault models show that surface-rupturing earthquakes are characterized by a large area of negative stress-drop surrounding the asperities, while buried earthquakes present positive or zero stress drop. In addition, the calibrated fault models that match the observations show that the average stress drop is independent of earthquake size for buried earthquakes, but scale dependent for surface-rupturing earthquakes. This suggests that, in the context of our parameterization, buried earthquakes follow self-similarity scaling, and surface-rupturing earthquakes break this self-similarity. We apply the calibrated dynamic models to simulate near-source ground motion consistent with observations that suggest that buried earthquakes generate stronger ground motion than surfacerupturing earthquakes at high frequency. We propose possible mechanisms that satisfy this observation, as follows: buried rupture has a hypocenter location below the asperity; this can produce strong directivity of the slip velocity function toward the free surface. That effect, in addition to a reduced fault area and low fracture energy during rupture, may be significant in enhancing high-frequency ground motion. On the other hand, surface-rupturing earthquakes have a shallow hypocenter, large fracture energy on the asperities, and enhanced energy absorption due to large areas of negative stress drop in the background area. These characteristics of large earthquakes inhibit severe directivity effects on the slip velocity function directly toward the free surface, reducing the high-frequency ground motion.
\end{abstract}

\section{Introduction}

A physical understanding of the earthquake rupture process can improve our capability for predicting ground motion, and therefore our assessment of seismic hazard. Numerical models of the dynamic rupture of earthquakes provide a convenient framework for incorporating physical constraints on the source physics into ground-motion simulations. These models usually idealize the earthquake rupture as a propagating shear crack on a frictional interface em-

"Now at Institute of Geophysics, ETH Hoenggerberg, CH-8093 Zurich, Switzerland bedded in a linearly elastic continuum. This idealization has proven to be a useful foundation for analyzing and simulating natural earthquakes (e.g., Andrews, 1976; Das and Aki, 1977; Day, 1982a,b; Olsen et al., 1997; Oglesby et al., 1998; Dalguer et al., 2001; Peyrat et al., 2001; Day et al., 2008), and we adopt it here.

The main difficulty with the use of dynamic models to simulate realistic earthquake ground motion is the lack of information to realistically parameterize the friction model and the state of stress in the crust. It is currently rather difficult to incorporate observational constraints into dynamic 
models. In the context of slip-weakening friction models, several attempts have been made to investigate what frictional parameters can be constrained with observations. For example, Ide and Takeo (1997), Bouchon et al. (1998), Guatteri and Spudich (2000), Pulido and Irikura (2000), Ide (2002), Mikumo et al. (2003), Zhang et al. (2003), and others studied strong ground-motion records of large earthquake to investigate whether the critical slip distance and fracture energy can be inferred from these observations. Theirs results show that the fracture energy is better constrained than the critical slip distance as pointed by Guatteri and Spudich (2000). The qualitative analysis of theses studies suggests that these parameters are scale dependent to the earthquake rupture process. Other attempts to constrain dynamic parameters use observations of earthquake scaling, as, for example, Abercrombie and Rice (2005). These authors argue that observations suggest that static stress drop is also scale dependent. They used the scale-dependence source parameters to constrain possible models of dynamic rupture.

Guided by a characterized source model, which consists of asperities and background areas (e.g., Somerville et al., 1999; Miyake et al., 2003), Dalguer et al. (2004) estimate the ratio between the dynamic stress drops on the asperity and background areas of the rupture surface, for surface rupturing and buried earthquakes, using the empirical model for earthquake kinematic parameters proposed by Somerville et al. (1999) as a constraint. The empirical model of Somerville et al. (1999) defines statistical slip characteristics in the asperity as a function of the average total slip. Dalguer et al. (2004) use quasi-dynamic modeling to estimate dynamic parameters consistent with this kinematic characterization. They infer that surface-rupturing earthquakes are characterized by a large area of negative stress drop surrounding the asperities, while buried earthquakes are better characterized by nonnegative stress drop.

In this study, we formulate a set of dynamic rupture models that combine the stress-drop constraints of Dalguer et al. (2004) with further constraints from empirical source scaling of seismic moment and rupture area. We refer to the resulting empirically constrained dynamic models as calibrated dynamic models. We then calculate ground motions from the calibrated models and compare results with observations that Somerville (2003) and Kagawa et al. (2004) interpret to indicate generic ground-motion differences between buried $\left(M_{\mathrm{w}} 6.7-7.0\right)$ and surface-rupturing $\left(M_{\mathrm{w}} 7.2-\right.$ 7.6) earthquakes. Their interpretation is that the former generate systematically stronger high-frequency ground motion than the latter. The simulations capture some of the groundmotion differences cited by Somerville (2003) and Kagawa et al. (2004), and we propose possible mechanisms to account for those differences.

For the calibration phase (i.e., in the search to find model parameters ensuring consistency with empirical scaling relations), we use quasi-dynamic simulations (simulations with fixed rupture velocity) calculated with inelastic-zone fault models (Dalguer and Day, 2006). For the ground-motion simulation phase, we use fully dynamic, spontaneous rupture modeling, applying the staggered-grid split node (SGSN) method recently developed by Dalguer and Day (2007). The SGSN method was implemented in the message-passing interface (MPI) finite difference code of the TeraShake platform (Olsen et al., 2006), which is scalable to thousands of processors (Dalguer et al., 2006), enabling high-performance execution for large-scale dynamic rupture models.

\section{Stress-Drop Calibration}

\section{Stress-Drop Distribution on the Fault}

Inversion of near-source ground motion (e.g., Wald and Heaton, 1994; Sekiguchi and Iwata, 2002) has revealed that fault-surface slip distributions of past earthquakes are highly heterogeneous and complex at all observable scales, with localized patches of large slip conventionally being referred to as asperities. This kinematic information can provide information relevant to earthquake dynamics, in the form of estimates of fault-plane stress change (e.g., Bouchon, 1997; Ide and Takeo, 1997; Day et al., 1998; Dalguer et al., 2002), which are also highly heterogeneous. Details of the absolute stress fields are currently not measurable, but it is likely that much of the heterogeneity in stress change is attributable to heterogeneities in the initial preearthquake stress state. A dynamic rupture simulation that begins from an initial stress state and friction coefficient distribution that together are consistent with the inferred fault-plane stress changes will, of course, reproduce the final slip distribution of the event. Thus, using stress change information from past earthquakes in this fashion may potentially put useful constraints on dynamic models, and hence on their groundmotion predictions.

Since our purpose is not to reproduce a single past event, rather to predict ground-motion characteristics of future earthquakes, it is appropriate to use statistical characteristics of past earthquakes to constraint stress-drop distributions. We use the characteristic slip models proposed by Somerville et al. (1999). These authors analyzed kinematic images from source inversions of past earthquakes and proposed statistical properties, such as (1) the average of combined asperity area is 0.22 times the total rupture area and (2) the ratio between the average asperity slip and average total slip is $D_{\text {asp }} /$ $D=2.0$. In previous work (Dalguer et al., 2004), we analyzed a series of forward dynamic rupture models, with fixed rupture velocity (quasi-dynamic models), and from them proposed ratios of stress-drop distribution on the fault $\left(\Delta \sigma_{b} / \Delta \sigma_{a}\right)$, where $\Delta \sigma_{b}$ and $\Delta \sigma_{a}$ are, respectively, the stress drop on the background area and asperity, that satisfy the foregoing empirical rules of Somerville et al. These ratios provide a simplified characterization of the stress-drop distributions of the asperity-source models. Here, we briefly summarize those results.

We represent buried earthquakes (those with no surface rupture) by a set of circular fault models (and checked that 
circular and rectangular faults, for buried earthquake, result in the same estimation of the metrics of interest), and surfacerupturing earthquakes by a set of rectangular fault models (the latter allowing us to take into consideration the generally larger aspect ratio of surface-rupturing earthquakes). In each case, we consider both single- and multiple-asperity models. The rectangular faults consist of earthquakes with $L \geq W_{\max }$, where $L$ and $W$ are, respectively, the length and width of the fault, and $W_{\max }$ is assumed to be $20 \mathrm{~km}$, representing the brittle crust of the earth. The fault models are calculated for $L$ up to $20 W_{\max }$. Forward dynamic rupture simulations are carried out for different stress-drop ratios $\left(\Delta \sigma_{b} / \Delta \sigma_{a}\right)$ in the range from -0.2 to 0.2 . These simulations used a fixed rupture velocity of 0.8 times the $S$-wave velocity and the simple slip-weakening friction model in the form given by Andrews (1976) with a critical slip-weakening distance $D_{c}=0.4 \mathrm{~m}$. The material properties are represented by the $P$-wave velocity $V_{p}=5.543 \mathrm{~km} / \mathrm{sec} S$-wave velocity $V_{s}=3.2 \mathrm{~km} / \mathrm{sec}$ and density $\rho=2.8 \mathrm{gr} / \mathrm{cm}^{3}$.

Figure 1 shows the average slip ratio $\left(D_{\text {asp }} / D\right)$ plotted with the stress-drop ratio $\left(\Delta \sigma_{b} / \Delta \sigma_{a}\right)$ for the set of dynamic solutions of the circular faults (buried earthquakes) and rectangular fault models (surface-rupturing earthquakes). Considering up to four asperities, the dynamic fault models that match the kinematic source characteristics of Somerville et al. (1999) have stress-drop ratios in the range from -0.1 to 0.1 for buried earthquakes and from -0.15 to 0.05 for surface-rupturing earthquakes, as indicated by the arrows in Figure 1. Based on the data presented by Somerville et al. (1999), we assume that the number of asperities increases with earthquake size, with the average number of asperities being 2.6 (as proposed by Somerville et al.), from which a reasonable inference is that buried faults have (on

(a)

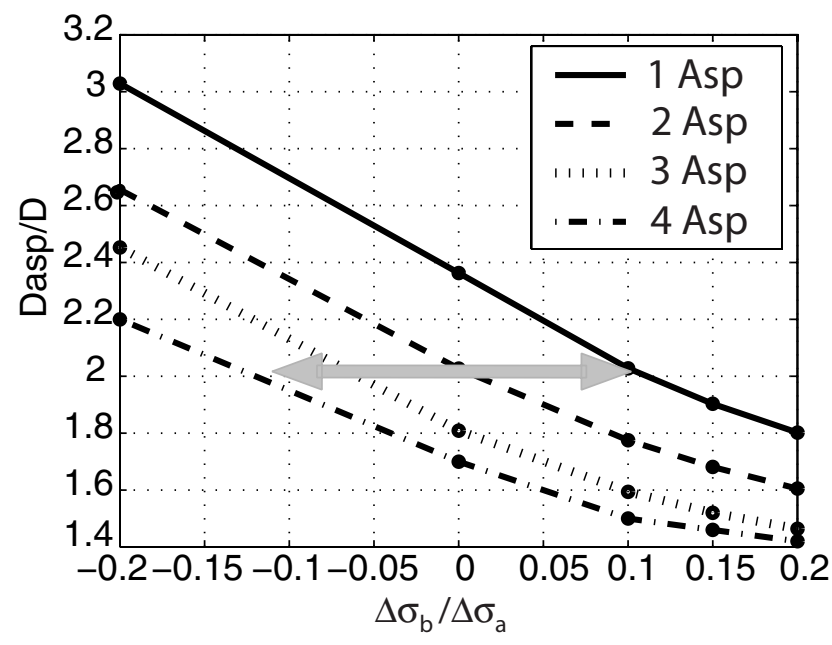

average) less than 2.6 asperities and surface-rupturing faults have (on average) more than 2.6 asperities. As a consequence, the stress drop surrounding the asperities is zero or positive for buried earthquakes and negative (with amplitude more than $10 \%$ of the stress drop of the asperity) for surface-rupturing earthquake. The difference in stress-drop distribution between buried and surface-rupturing earthquake is marked, and this systematic difference may be relevant to the physics of the rupture mechanism. For example, the large area of apparent negative stress drop surrounding the asperities during large earthquakes may actually reflect energy losses from a large area of damage zone off fault where energy is dissipated, or a change in frictional parameters at shallow depth to favor velocity strengthening. However, here we take a phenomenological approach, using the results to calibrate the asperity/background stress-drop ratio within the context of our simple parameterization of ground-motion simulation models.

\section{Stress-Drop Scaling with Earthquake Size}

Empirical source scaling of seismic moments and rupture area provides a guideline to constrain the variability of the macroscopic rupture parameters, such as seismic moment, rupture area, and average stress drop with earthquake size. Several scaling models, derived from past earthquakes, were presented in the literature (e.g., Kanamori and Anderson, 1975; Scholz, 1982; Wells and Coppersmith, 1994; Somerville et al., 1999; Mai and Beroza, 2000; Irikura and Miyake, 2001; Hanks and Bakun, 2002; Scholz, 2002; Irikura et al., 2004). Here we use the empirical model proposed by Irikura et al. (2004) based on Irikura and Miyake (2001). These authors proposed three-stage scaling relationship between seismic moment and rupture area, as shown in

(b)

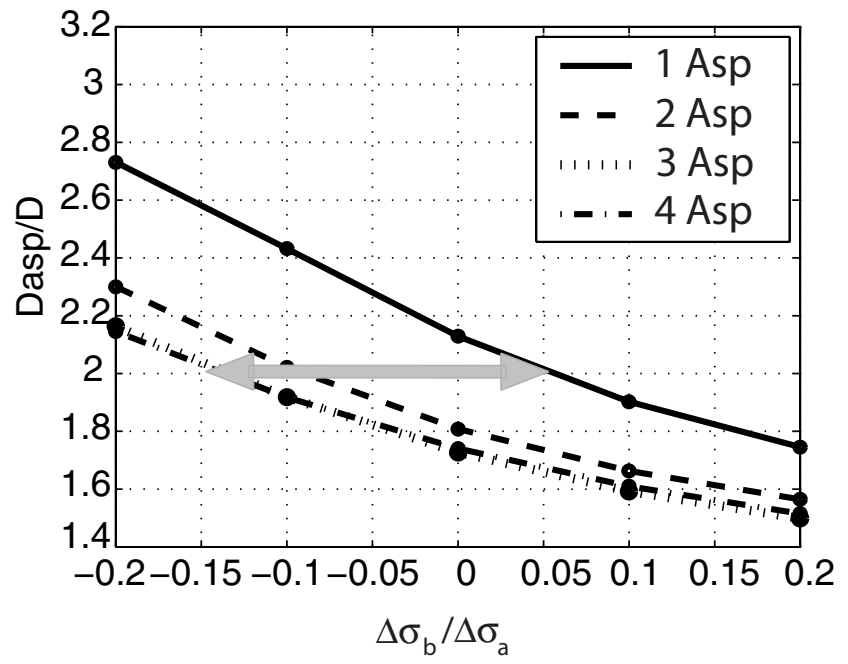

Figure 1. Average slip ratio $\left(D_{\text {asp }} / D\right)$ plotted with the stress-drop ratio $\left(\Delta \sigma_{b} / \Delta \sigma_{a}\right)$ for the dynamic solution of the buried earthquake (a) and surface-rupturing earthquakes (b) calculated by Dalguer et al. (2004). The arrow specifies the band of the stress-drop ratios that lies on the characterized slip model proposed by Somerville et al. (1999). 
Figure 2. This scaling model is empirically constrained with a statistical analysis of kinematic source models estimated from waveform inversion of strong-motion records for crustal earthquakes (Somerville et al., 1999; Miyakoshi, 2002; Asano et al., 2005) and earthquake catalogs (Wells and Coppersmith, 1994). The analyzed data range from moment magnitude $M_{\mathrm{w}} 5.7$ to $M_{\mathrm{w}}$ 7.6. The first scaling line of this empirical model, for moderate-size earthquakes, is expressed by the empirical equation proposed by Somerville et al. (1999):

$S=\left(2.23 \times 10^{-15}\right) M_{0}^{2 / 3} \quad$ for $M_{0}<7.5 \times 10^{25}$ dyne $\mathrm{cm}$.

The second line, proposed by Irikura et al. (2004) for larger earthquakes, is represented by

$S=\left(4.59 \times 10^{-11}\right) M_{0}^{1 / 2} \quad$ for $M_{0} \geq 7.5 \times 10^{25}$ dyne $\mathrm{cm}$,

and the third line, also proposed by Irikura et al. (2004) for the largest earthquakes, is represented by

$$
S=\left(5.30 \times 10^{-25}\right) M_{0} \quad \text { for } M_{0} \geq 7.5 \times 10^{27} \text { dyne } \mathrm{cm},
$$

where $S$ is the fault area in $\mathrm{km}^{2}$ and $M_{0}$ is the seismic moment in dyne centimeters.

Our target is to constrain the variability of the average stress drop with the empirical scaling model of Irikura et al. (2004) shown in Figure 2. For that, we perform 3D simula-

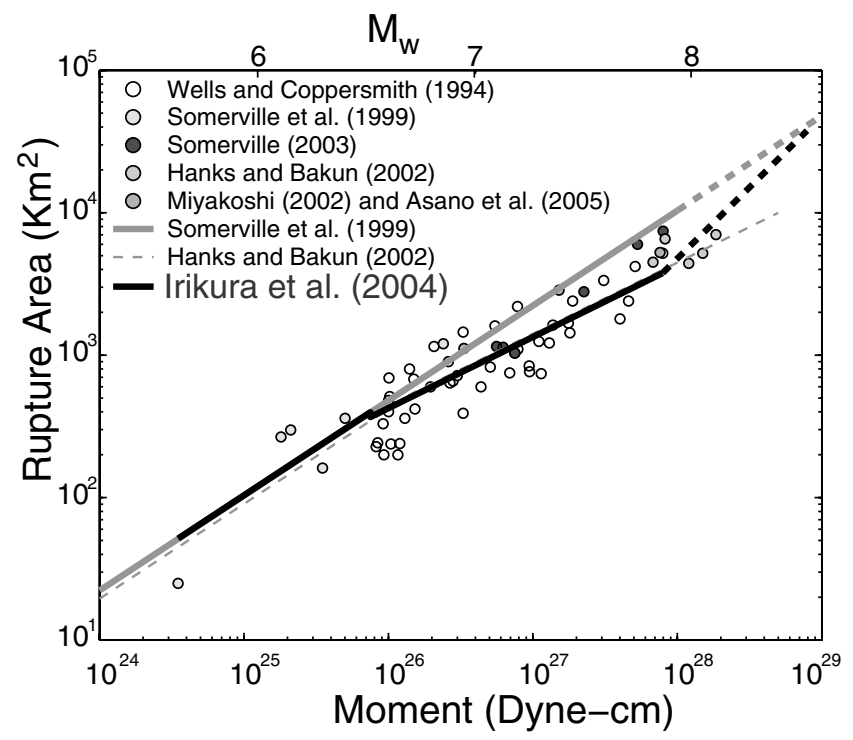

Figure 2. Empirical scaling models of seismic moment and rupture area, proposed by Irikura et al. (2004) (thick black solid line and thick black dashed line), Hanks and Bakun (2002) (thin gray dashed line), and Somerville et al. (1999) (thick gray solid line and thick gray dashed line). tions of dynamic faulting for a series of single- and multipleasperity source models of rectangular faults for surface rupturing and buried earthquakes. We expect that the stress distribution will affect the moment/area relation principally through the average stress drop, and we will initially examine the effect without introducing the stress-drop distribution differences (asperity/background ratios) inferred previously. However, in a later section, we will verify that adding that complexity does not alter the conclusion. The material and friction law characteristics are the same as the models described in the previous section. Our simulations consist of vertical strike slip faults. For buried earthquakes, the fault is located at 3-km depth and has one asperity. Fault models with fault area $(L \times W) 12.5 \times 12.5,17 \times 17$, and $20 \times 20$ in $\mathrm{km}^{2}$ are used. For surface-rupturing earthquakes, the faulting breaks the free surface, and the faults have a width $(W)$ of $20 \mathrm{~km}$, corresponding to the maximum $W$ that represents the brittle crust of the earth. The fault length $L$ (in kilometers) and number of asperities (nasp) for each model are $(L$, nasp $)=(20,1),(40,2),(100,3),(200,4),(300,4)$, and $(400,4)$.

Models with stress drop on the asperity $\left(\Delta \sigma_{a}\right)$ equal to 8 Mpa (1.76 Mpa), 10.5 Mpa (2.31 Mpa), 15 Mpa (3.3 Mpa), and $20 \mathrm{Mpa}$ (4.4 Mpa) are used for surface-rupturing and buried earthquakes. The values in parentheses are the corresponding average stress drop for each model. The stress drop on the background area is zero for all the models. The ratio between the combined asperity area and total rupture area is equal to 0.22 . Notice that buried faults are now modeled by square faults, and not by circular fault as in the previous section, so that all faults (buried and surface rupturing) can be characterized by the ratio $L / W$.

Figure 3 shows the final slip distribution (for the case of models with stress drop on the asperity equal to $10.5 \mathrm{Mpa}$ ) of some of the faults calculated with the dynamic rupture simulation. Using the set of dynamic rupture models, we verified that for the same fault rupture area, the relation

$$
\frac{M_{01}}{M_{02}} \approx \frac{\Delta \overline{\sigma_{1}}}{\Delta \overline{\sigma_{2}}}
$$

is satisfied, where $M_{0}$ and $\Delta \bar{\sigma}$ are, respectively, the seismic moment and average stress drop, and the subscripts 1 and 2 denote two different earthquakes (earthquake 1 and 2).

Equation (4) permits estimating average stress drops consistent with the empirical scaling model. This estimation suggests a variation of average stress drop as shown in Figure 4 and summarized as follows:

$$
\Delta \bar{\sigma} \sim 1.5 \mathrm{Mpa} \quad \text { for } L \leq 1.5 W_{\max }
$$

$$
\begin{aligned}
& \Delta \bar{\sigma} \sim 1.5 \mathrm{Mpa} \text { to } 5.3 \mathrm{Mpa} \\
& \text { for } 1.5 W_{\max }<L \leq 10 W_{\max }
\end{aligned}
$$

$$
\Delta \bar{\sigma} \sim 5.3 \mathrm{Mpa} \quad \text { for } L>10 W_{\max }
$$


(a)

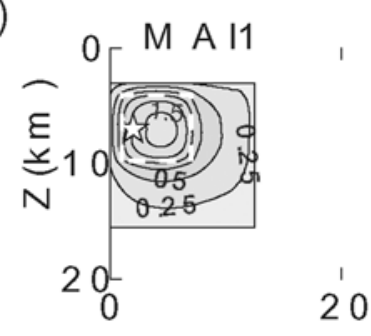

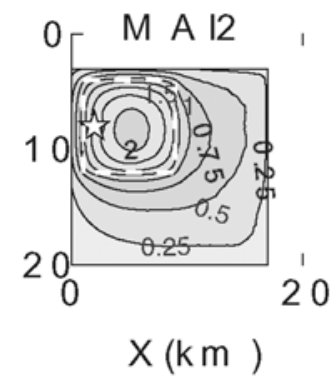

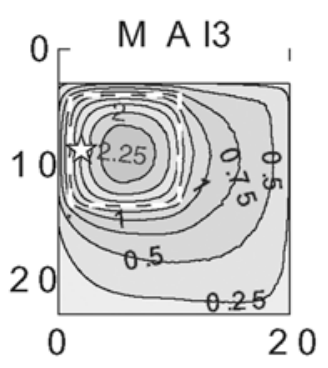

$\mathrm{M} \mathrm{A} \mathrm{I5}$

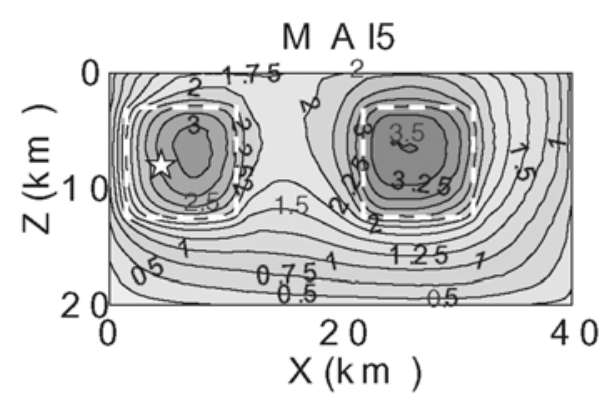

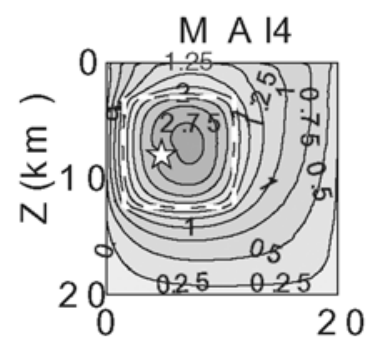
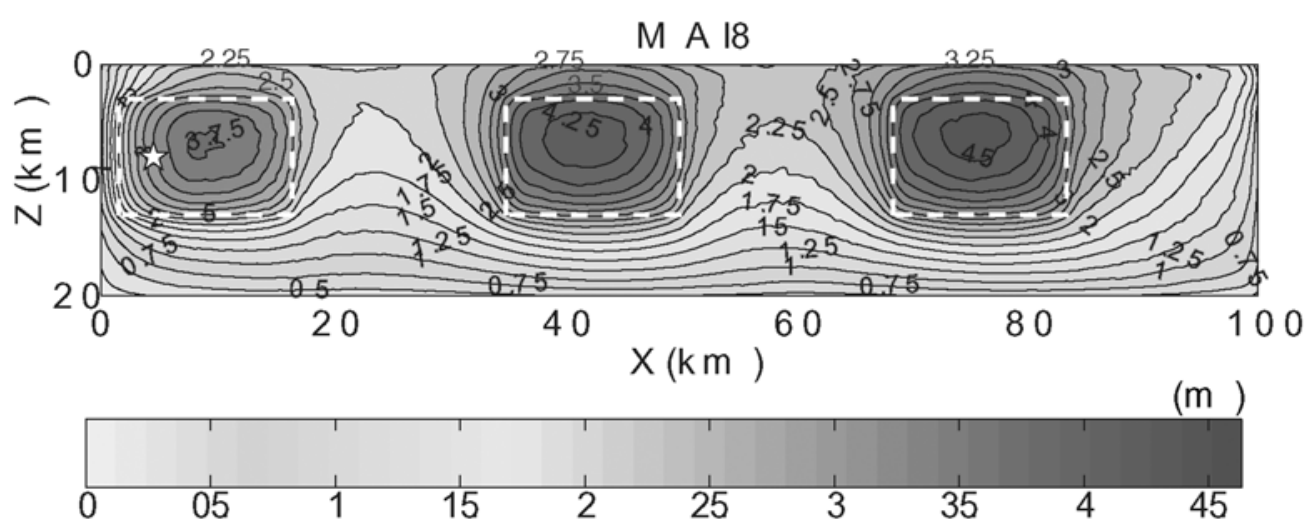

(b)

M A I10
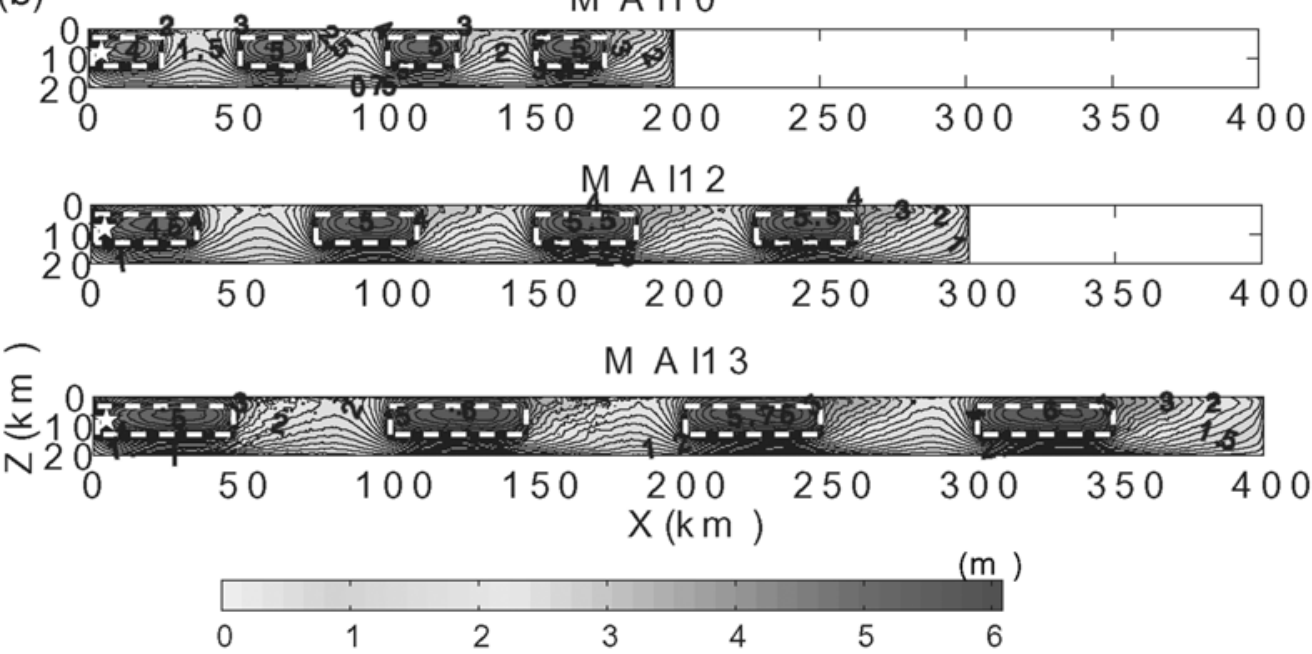

Figure 3. (a) Final slip distribution of some rectangular asperity models calculated with dynamic rupture simulation for the case with stress drop in the asperity $\Delta \sigma_{a}=10.5 \mathrm{Mpa}$. MAI1 to MAI3 are buried earthquakes, and the rest correspond to surface-rupturing earthquakes. The white dashed lines border the asperity area, and the star is the hypocenter. (b) Final slip distribution of the largest fault models of surface-rupturing earthquakes, calculated with dynamic rupture simulation for the case with stress drop on the asperity $\Delta \sigma_{a}=10.5 \mathrm{Mpa}$. The white dashed lines border the asperity area, and the star is the hypocenter. 


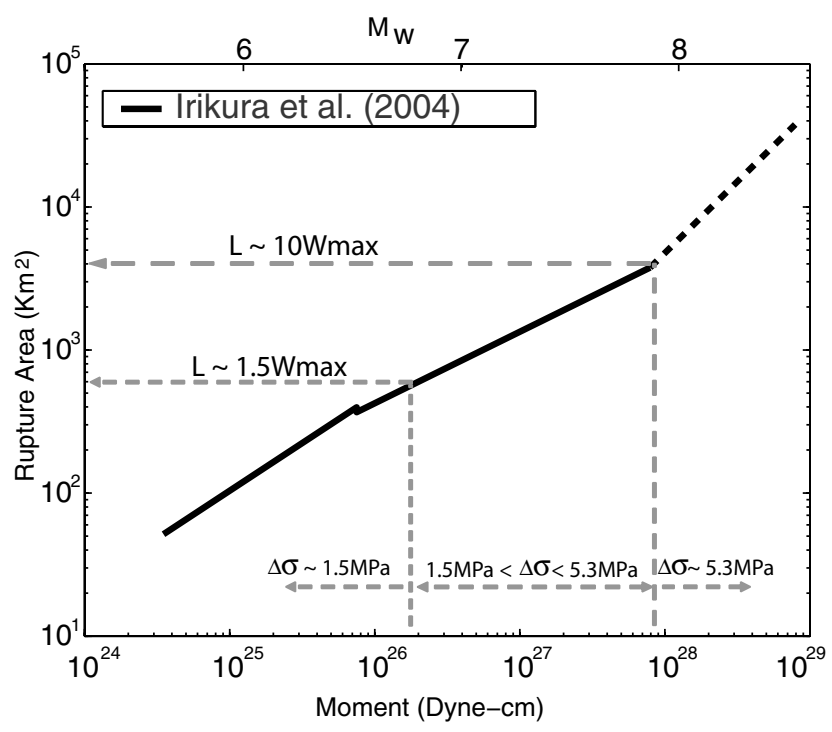

Figure 4. Average stress-drop variation, calculated from the dynamic rupture models, that lies on the empirical scaling models of seismic moment and rupture area proposed by Irikura et al. (2004).

Equation (5a) is consistent with the self-similar scaling model proposed by many authors (e.g., Hanks, 1977), that is, the stress drop is independent of the earthquake size. But this self-similarity is sustained for buried earthquakes only. Equation (5b), which represents surface-rupturing earthquakes, breaks this self-similarity, and the stress drop becomes earthquake-size dependent. Scale-dependent earthquake were proposed by many authors (e.g., Kanamori et al., 1993; Abercrombie, 1995). Equation (5c) is a projection of our numerical model, because we were not able to model earthquake larger than $L=20 W_{\max }$. The few points given by the model with $L>10 W_{\max }$ suggest that the stress drops turns out to be independent of the earthquake size, but this need to be verified with further research.

We must acknowledge that there are uncertainties in this calibration procedure that are large but difficult to quantify due to the fact that we subsume the complex mechanics of large earthquakes into only a few simple dynamic parameters. For example, and just to suggest one possibility, some or all of the slope change around $L \sim 1.5 W_{\max }$ may be actually be due to slip or distributed shear below the brittle-ductile transition rather than systematic stress-drop variations.

\section{Hypocenter Location and Fracture Energy}

\section{Effect of Hypocenter Location}

Hypocenter location may play an important role in influencing ground-motion generation and rupture propagation. Mai et al. (2005) analyzed the relationship of hypocenter location to slip distribution for more than 50 earthquakes. They found that most of these earthquakes have hypocenters located in regions of large slip or very close to those regions, suggesting an association of hypocenter location with asperities, that is, with regions of high stress drop. We explore the effects of the hypocenter location on the peak slip velocity (using slip velocity as a simple way of quantifying effects on ground-motion amplitudes). For that purpose, two buried faults located at 3-km depth from the free surface are used. One fault has the dimensions $L \times$ $W=25 \times 17 \mathrm{~km}$, and one asperity with $9.5-\mathrm{km}$ length and $9.5-\mathrm{km}$ width. The other fault has $L \times W=12.5 \times 17 \mathrm{~km}$, and a narrow asperity with $5-\mathrm{km}$ length and $9.5-\mathrm{km}$ width. The two models have stress drop 10.0 Mpa on the asperity, and zero stress drop outside the asperity. The critical slip distance for the first model is $0.4 \mathrm{~m}$, and for the second model $0.2 \mathrm{~m}$ (with a corresponding factor of 2 reduction in fracture energy for the second model). The material properties and friction conditions are the same as for the models described in the previous sections.

Figure 5 shows the peak slip velocity distribution for these two models. The upper figures are the results of the first fault model with different hypocenter location as shown by the black star. The model with deeper hypocenter generates the largest peak slip velocity due to the directivity effect of rupture propagation toward the free surface. For the second model, we use only a deep hypocenter, as shown in the bottom figure. In this latter model, the peak slip velocity is further enhanced as a result of reduced energy absorption due to the smaller critical slip distance. This simple dynamic rupture model indicates that a deep hypocenter location can produce directivity leading to concentration of the slip velocity function toward the free surface. That effect, in addition to a reduced fault area and low fracture energy during rupture, may be significant in enhancing high-frequency ground motion. We investigate the fracture energy effect in the next section.

\section{Effect of Fracture Energy}

As a exploratory step before applying the calibrated models to ground-motion simulation, we consider separately the effect of fracture energy, now using the spontaneous rupture model. Theoretical and empirical studies of fracture energy (e.g., Ide and Takeo, 1997; Bouchon et al., 1998; Guatteri and Spudich, 2000; Ide, 2002; Tinti et al., 2005; Mai et al., 2006) suggest that fracture energy is scale dependent, varying with the spatial scale of the earthquake rupture. Mai et al. (2006) analyzed scaling properties of fracture energy derived from dynamic rupture models of past earthquakes, concluding that the fracture energy scales markedly differently for surface ruptures than it does for buried rupture. Their study suggests that a large earthquake consumes more fracture energy as the rupture expands and reaches the free surface, compared with a confined rupture.

We explore the effects of the fracture energy, again using the peak slip velocity as a measure of ground-motion excitation. For that, one surface fault is used. The fault has the dimensions $L \times W=100 \times 20 \mathrm{~km}$, and four asperities as distributed in Figure 5. The fault model has stress drop 

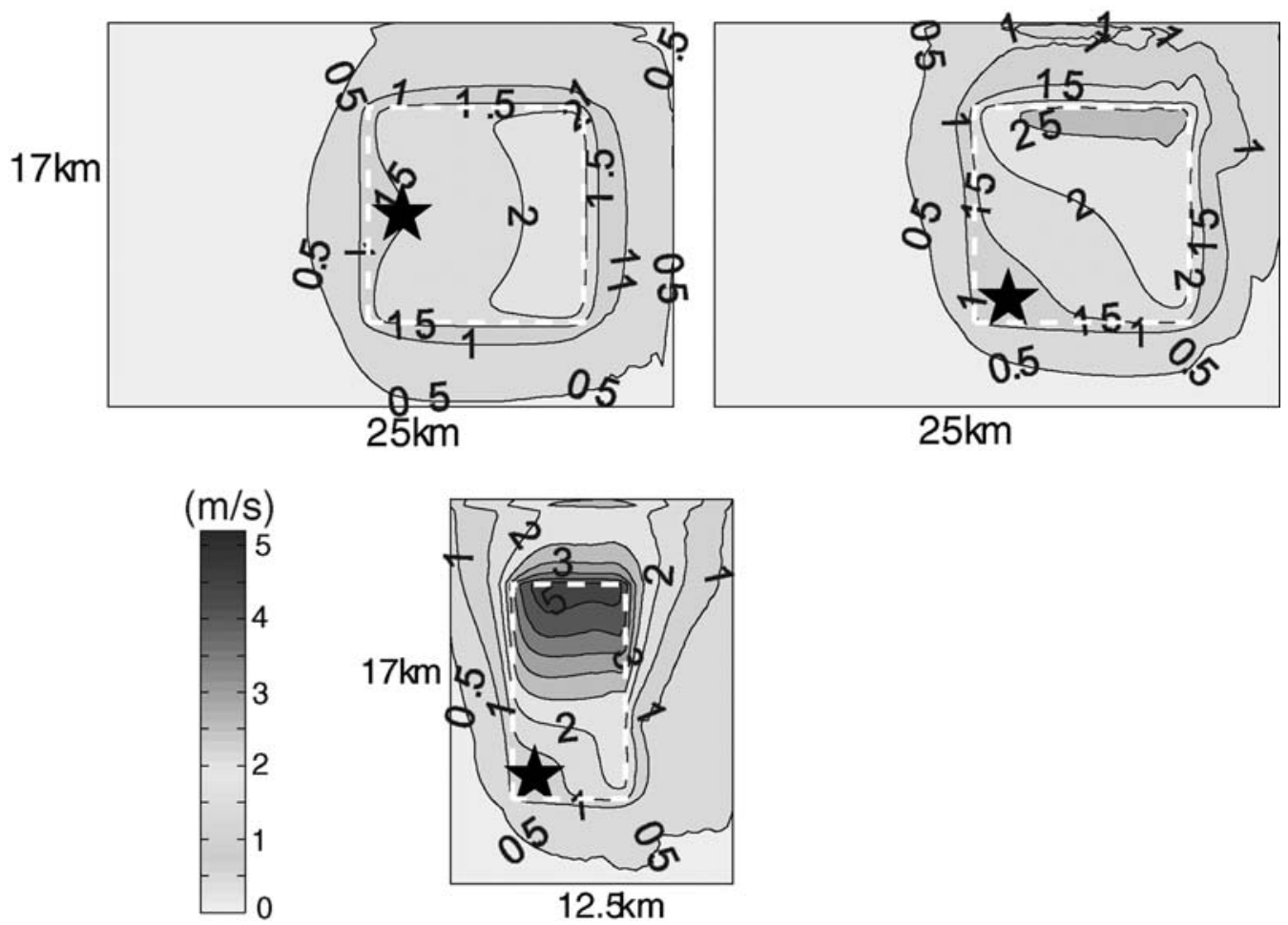

Figure 5. Peak slip velocity distribution calculated from dynamic rupture simulation for two buried-fault models with stress drop in the asperity area $\Delta \sigma_{a}=10.0 \mathrm{Mpa}$, and zero stress drop outside the asperity. The critical slip distance for the upper fault models is $0.4 \mathrm{~m}$ and $0.2 \mathrm{~m}$ for the bottom fault model. The star represents the hypocenter location. The white dashed lines border the asperity area.

10.0 Mpa on the asperity, and zero stress drop outside the asperity. We simulate two ruptures, with high and low fracture energy, respectively. The fracture energy is varied by varying the slip-weakening distance $\left(D_{c}\right)$, using $D_{c}=0.4$ and $0.8 \mathrm{~m}$, respectively, for the low- and high-fracture energy model. The material properties and other frictional parameters are the same as in the models described previously.

As shown in Figure 6, the large-fracture energy model (bottom figure) has overall lower slip velocities, as expected, and diminished directivity effects on the slip velocity function due to large energy absorption in the fracture development. This effect on the slip-velocity function may be significant in reducing the high-frequency ground motion.

\section{Application of the Calibrated Dynamic Models to Simulate Near-Source Ground Motion of Surface-Rupturing and Buried Earthquakes}

Given the type of earthquake (buried or surface rupture) and the size of the earthquake (quantified by rupture area, seismic moment, and/or moment magnitude), we form a dynamic stress-drop distribution calibrated to the $\Delta \sigma_{b} / \Delta \sigma_{a}$ ratio shown in Figure 1 and the average stress-drop scaling shown in Figure 4. Then we apply the calibrated dynamic models to study the differences of faulting and near-source ground motion of surface-rupturing and buried earthquakes, with the goal of exploring possible explanations of recent observations of Somerville (2003) and Kagawa et al.
(2004). These authors suggest that buried earthquakes (buried rupture with $M_{\mathrm{w}}$ 6.7-7.0) generate stronger ground motion than surface-rupturing earthquakes (large surface rupture with $M_{\mathrm{w}}$ 7.2-7.6) around a period of $1 \mathrm{sec}$. In the context of the calibrated dynamic model, we explore the mechanism of surface rupturing and buried earthquakes and propose a parameter set for each type that is consistent with the observed differences of near-source ground motion. The effects of hypocenter location and fracture energy noted in previous sections help guide this exploration.

We use two buried and two surface-rupturing fault models with the parameters specified in Table 1 and shown in Figure 7. The $P$-wave velocity $\left(V_{p}\right), S$-wave velocity $\left(V_{s}\right)$, and density are $6.0 \mathrm{~km} / \mathrm{sec}, 3.464 \mathrm{~km} / \mathrm{sec}$, and $2.67 \mathrm{gr} /$ $\mathrm{cm}^{3}$, respectively. The rupture nucleates artificially in a circular patch with radius $R$ located inside the first asperity of each model, and then it spontaneously propagates along the defined fault. The values of $S_{e}$ and $D_{c}$ shown in Table 1 were selected, from results of many dynamic rupture simulations, for their consistency with the difference of ground motion between surface-rupturing and buried earthquakes, as observed by Somerville (2003). The hypocenter locations, as shown in Figure 6, were also intentionally selected a posteriori for this purpose. A grid size of $100 \mathrm{~m}$ is used for the simulations. With this numerical resolution, we adequately model wavelengths larger than six time the grid size, permitting to represent waves up to $5.0 \mathrm{~Hz}$. 
Table 1

Model Parameters for the Dynamic Rupture Simulations

\begin{tabular}{lcccc}
\hline & \multicolumn{2}{c}{ Buried (3-km Depth) } & \multicolumn{2}{c}{ Surface Rupturing } \\
\cline { 2 - 5 } Model Name & B1 & B2 & S2 & S3 \\
\hline $\mathrm{L} \times \mathrm{W}\left(\mathrm{km}^{2}\right)$ & $12.5 \times 17.0$ & $25.0 \times 17.0$ & $75.0 \times 20.0$ & $100.0 \times 20.0$ \\
Asperity size $\left(\mathrm{km}^{2}\right)$ & $6.0 \times 7.8$ & $9.6 \times 9.6$ & $10.5 \times 10.5$ & $10.5 \times 10.5$ \\
$\mathrm{~N}^{\circ}$ asperities & 1 & 1 & 3 & 4 \\
$D_{c}(\mathrm{~m})$ & 0.2 & 0.3 & 1.6 & 1.6 \\
$\Delta \sigma_{a}(\mathrm{Mpa})$ & 6.82 & 6.82 & 17.8 & 21.8 \\
$\Delta \sigma_{b}$ (Mpa) & 0.0 & 0.0 & -1.78 & -2.18 \\
$S_{e}$ (first asperity) $(\mathrm{Mpa})$ & 6.82 & 6.82 & 17.8 & 21.8 \\
$S_{e}$ (rest) $($ Mpa) & 2.4 & 2.4 & 3.56 & 4.36 \\
$G_{c}$ (first asperity) $\left(\mathrm{J} / \mathrm{m}^{2}\right)$ & $1.36 \times 10^{6}$ & $2.05 \times 10^{6}$ & $28.5 \times 10^{6}$ & $34.9 \times 10^{6}$ \\
$G_{c}$ (other asperities) $\left(\mathrm{J} / \mathrm{m}^{2}\right)$ & - & -1 & $17.1 \times 10^{6}$ & $20.9 \times 10^{6}$ \\
Grid size $(\mathrm{km})$ & 0.1 & 0.1 & 0.1 & 0.1 \\
Nucleation radio $R(\mathrm{~km})$ & 1.3 & 1.5 & 2.5 & 2.5 \\
Time step (sec) & 0.0065 & 0.0065 & 0.0065 & 0.0065 \\
\hline
\end{tabular}

$D_{c}$ is critical slip distance, $S_{e}$ is strength excess (static strength minus initial shear stress), $\Delta \sigma_{a}$ and $\Delta \sigma_{b}$ are, respectively, dynamic stress drop on the asperity and outside the asperity, and $G_{c}$ is the surface fracture energy.

Recall that the model calibration was done using quasidynamic simulations, and by doing separate calibrations of the ratio $\Delta \sigma_{b} / \Delta \sigma_{a}$ and of the average stress drop. We now check whether the full spontaneous rupture simulations based on the calibrated parameters remain in agreement with the empirical parameter estimates. The moment magnitude $\left(M_{\mathrm{w}}\right)$, stress-drop ratio $\left(\Delta \sigma_{b} / \Delta \sigma_{a}\right)$, the average slip ratio $\left(D_{\text {asp }} / D\right)$, and the ratio between the combined asperity area and total rupture area $\left(A_{\text {asp }} / A\right)$ of each model are specified in Table 2. The slip ratio, as well as the asperity-area ratios, are in good agreement with the empirical targets shown in Figure 1 . The simulated earthquakes also still follow the empiri- cal moment-area scaling relation as shown in Figure 8. Thus, the buried and surface-rupturing earthquakes simulated from the proposed calibrated dynamic models maintain these statistical properties of real past earthquakes.

Figure 9 shows the rupture-time contours from the 3D spontaneous dynamic rupture simulation of the four models described in Figure 7 and Table 1. The results of the buried earthquakes (B models) show smooth or well-defined rupture velocity (subshear) toward the free surface. However, for the surface-rupturing earthquakes, rupture propagation is more complex as a result of interactions of the rupture with multiple asperities, low-stress regions, and the free surface. When

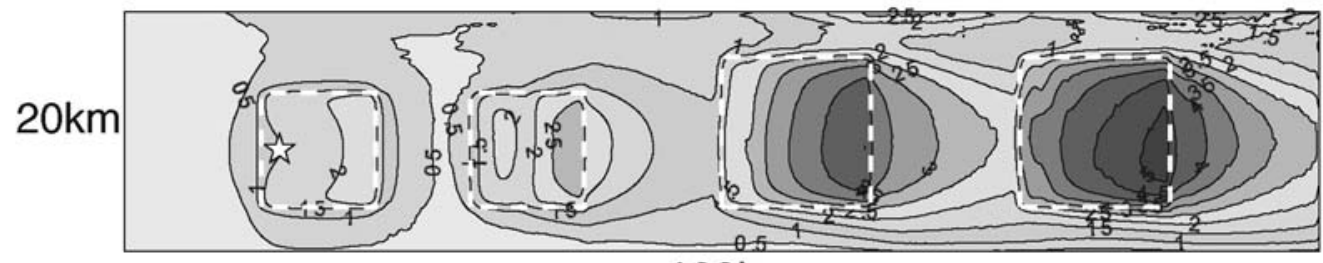

$100 \mathrm{~km}$
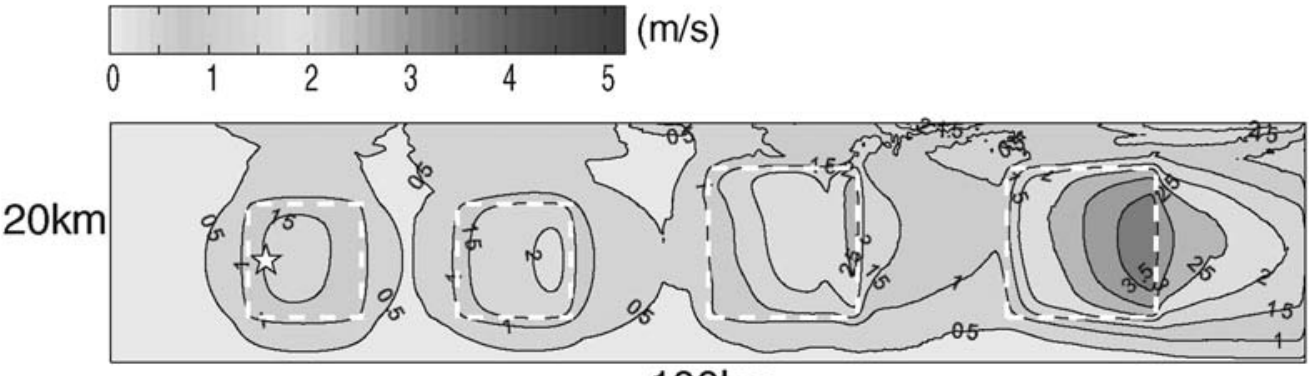

$100 \mathrm{~km}$

Figure 6. Peak slip velocity distribution calculated from dynamic rupture simulation for two surface-rupturing earthquakes, respectively, with low fracture energy $\left(D_{c}=0.4 \mathrm{~m}\right.$, upper figure) and large fracture energy $\left(D_{c}=0.8 \mathrm{~m}\right.$, bottom figure). The fault models have stress drop in the asperity area $\Delta \sigma_{a}=10.0 \mathrm{Mpa}$, and zero stress drop outside the asperity. The star represents the hypocenter location. The white dashed lines border the asperity area. 
Table 2

Characteristic Parameters of Dynamic Rupture Simulations

\begin{tabular}{lcccc}
\hline & \multicolumn{2}{c}{ Buried (3-km Depth) } & \multicolumn{2}{c}{ Surface Rupturing } \\
\hline Model name & $\mathrm{B} 1$ & $\mathrm{~B} 2$ & $\mathrm{~S} 2$ & $\mathrm{~S} 3$ \\
$M_{\mathrm{w}}$ & 6.3 & 6.6 & 7.4 & 7.5 \\
$\Delta \sigma_{b} / \Delta \sigma_{a}$ & 0.0 & 0.0 & -0.1 & -0.1 \\
$D_{\text {asp }} / D$ & 2.1 & 2.3 & 1.9 & 1.9 \\
$A_{\text {asp }} / A$ & 0.26 & 0.22 & 0.22 & 0.22 \\
\hline
\end{tabular}

the rupture front is between asperities, the rupture velocity sometimes reduces to almost zero, but then, when it reaches an asperity, the rupture recovers and accelerates, reaching to supershear rupture velocity after crossing the asperity (a qualitative behavior that has been documented in previous simulations, e.g., Day, 1982b). When the rupture approaches the free surface, the rupture becomes incoherent and the rupture velocity is not well defined, perhaps because (in the models) the entire near-surface region has low stress drop, and rupture through this zone is largely being driven from the asperities below. This characteristic of the rupture velocity in the surface-rupturing earthquake simulations, if it applies to real earthquakes, may reduce the classic rupture directivity effect on the ground motion, especially very close to the fault (Olsen et al., 2008).

Figure 10 shows the final slip and the peak slip velocity from the dynamic rupture simulations. The final-slip amplitudes are quite different between the surface-rupturing and buried earthquakes (as expected, simply from the stress-drop scaling we used to match the empirical moment-area relations, and the smaller fault surfaces of the buried ruptures). However, the peak slip velocities from the buried earthquakes are comparable in amplitude to those of the surface-rupturing earthquakes. The differences are mainly in
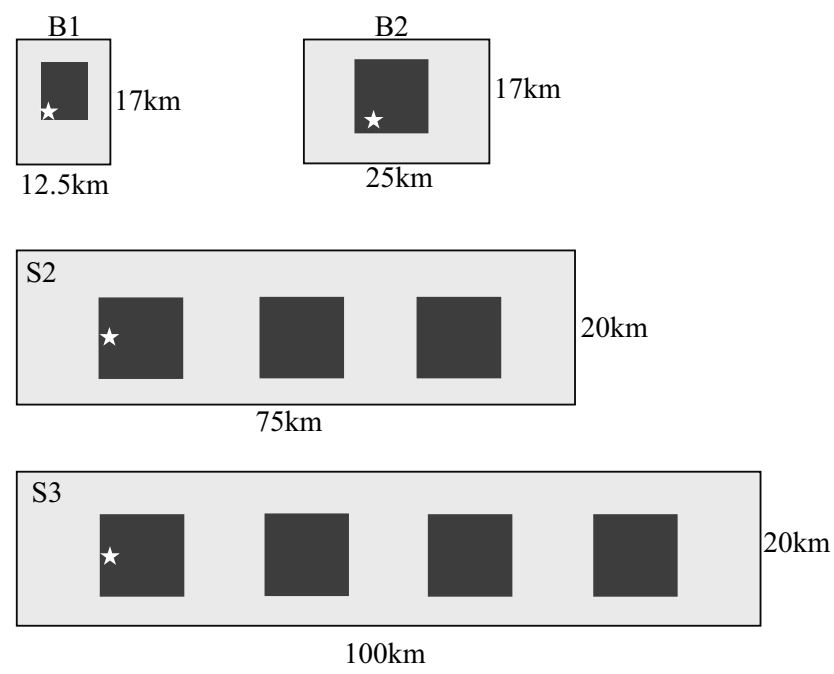

Figure 7. Fault models for dynamic rupture simulation of buried earthquakes (B models) and surface-rupturing earthquakes (S models). the directionality of the peak slip velocities. For the buried earthquakes, the peak slip velocity grows toward the free surface, following a relatively simple rupture directivity effect. For the surface-rupturing earthquakes, the largest peak slip velocities concentrate mainly on the asperity areas. The directivity effect on the slip velocity of the surface-rupturing earthquakes was inhibited by the high fracture energy on the asperities, the negative background stress drop (which produces enhanced energy absorption), and the near-surface rupture incoherence described earlier.

Finally, we examine the ground motion predicted by the dynamic models. Figure 11 shows the location of the receivers where velocity ground motion is simulated. Figure 12 shows low-pass and high-pass filtered peak ground velocity at the receivers located along the lines 1,2, and 3, as specified in Figure 11. The low- and high-pass filters each with cutoff frequency at $1 \mathrm{~Hz}$. The low-frequency ground velocity is much higher for the surface-rupturing simulations, as would be expected, because those simulations have higher moments and slip. However, the buried simulations have ground velocity comparable in amplitude to that of the surface-rupturing simulations, and in some cases even larger. The high-frequency fault-normal component for the buried earthquakes is especially strong. The highest amplitudes are on the trace of the fault, and gradually diminish as the site moves away from the trace of the fault. Away from the fault, the parallel component of the buried earthquakes also develops high-frequency amplitudes comparable to those of the surface-rupturing earthquake. Another interesting characteristic, seen in this figure, is the variation of the amplitude of the peak velocity along the strike direction of the surfacerupturing earthquakes. This variation of amplitude does not show the classic rupture directivity effect in the high-

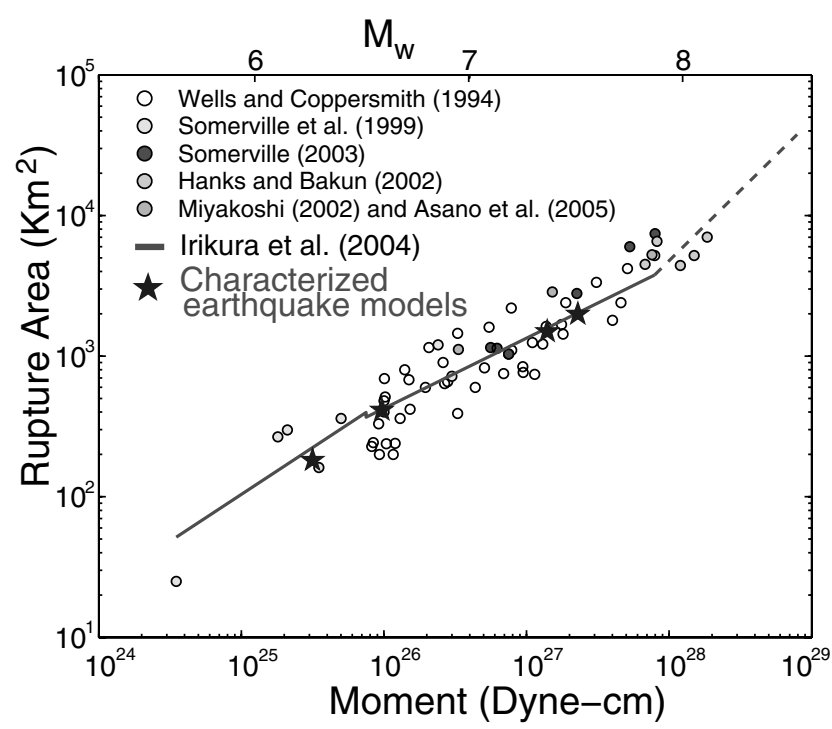

Figure 8. Identification of the calibrated dynamic models (black stars) on the empirical source-scaling model of Irikura et al. (2004). 

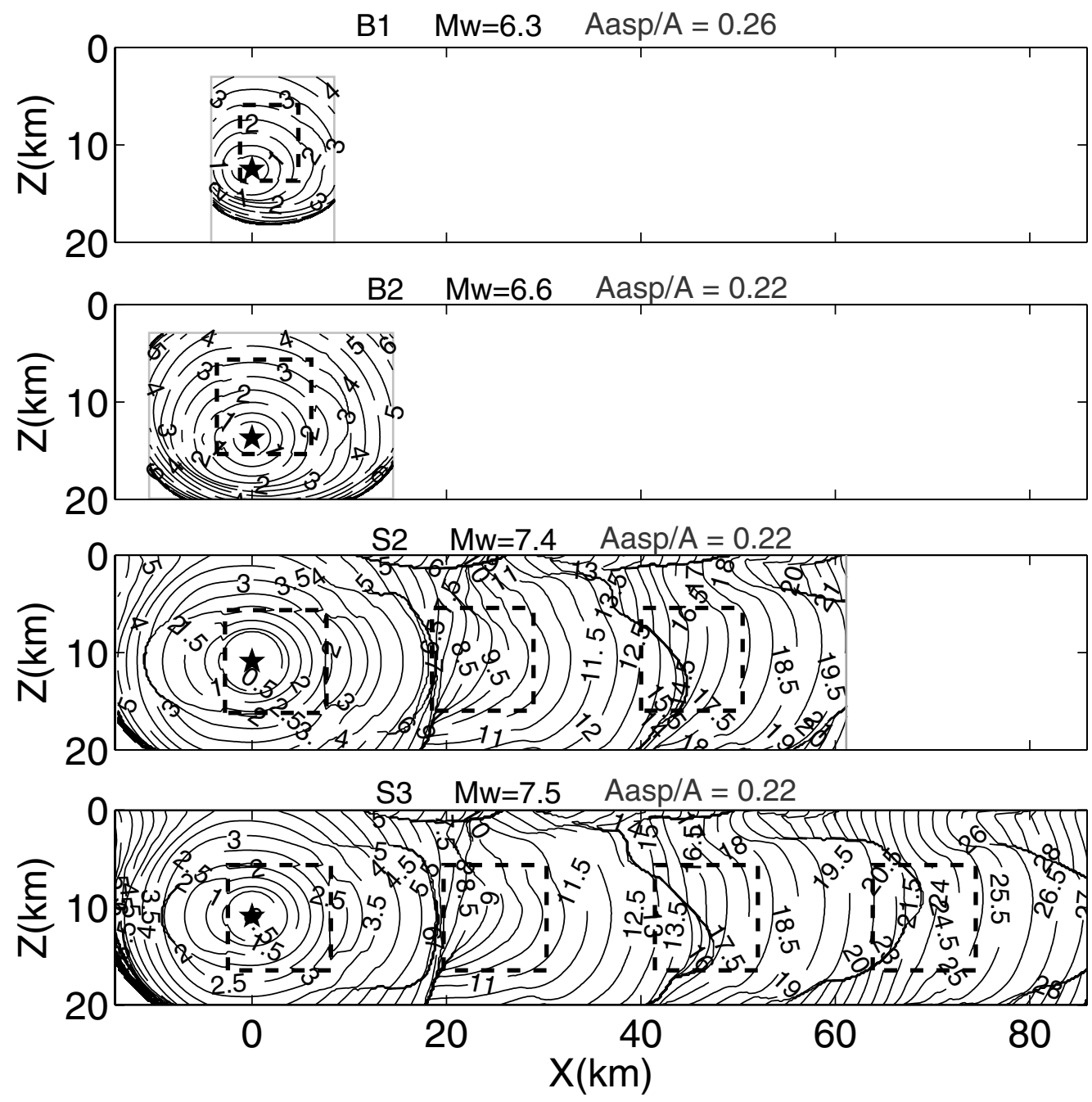

Figure 9. Rupture-time contours from the 3D spontaneous dynamic rupture simulation of the buried (B models) and surface-rupturing (S models) earthquakes. The black dashed line represents the asperities and the star the hypocenter location.

frequency band. As mentioned earlier, the high fracture energy on the asperity, negative stress drop outside the asperity, and incoherence of rupture combine to reduce the rupture directivity effect on the ground motion.

Figure 13 shows the comparison of time history and response spectra of the normal component of the ground velocity from the surface-rupturing and buried earthquakes, at receiver, as specified in Figure 11. Notice that the receivers are located at different locations for the different events. The locations were selected to illustrate the maximum ground motion for each event. As shown by this figure, the buried events have spectral peaks that are shifted toward a shorter period, relative to the surface-rupturing events. The velocity response spectra show clearly that the high-frequency ground motion of the buried events is higher than that of the surfacerupturing events. On the other hand, the low frequency ground motion of the surface-rupturing events is higher than that of the buried events, consistent with the higher moment and slip of the former. These results are qualitatively consistent with the observations reported by Somerville (2003).

\section{Discussion and Conclusions}

The main impediment to the use of spontaneous rupture models in earthquake ground-motion prediction is probably the limited state of our knowledge of the friction law and stress (and other) conditions on faults prior to rupture in large events. In the long term, these limitations may be overcome through detailed experimentation and modeling at the microscale, combined with model testing through full-scale simulation of ground-motion observations from many individual earthquakes. In the short term, an alternative is to invoke some of the spirit of kinematic ground-motion modeling, but within the framework of dynamically consistent models of rupture. We can assume simple parameterizations to describe the friction law and stress state, perform simulations that sample the parameter space, and then calibrate those 


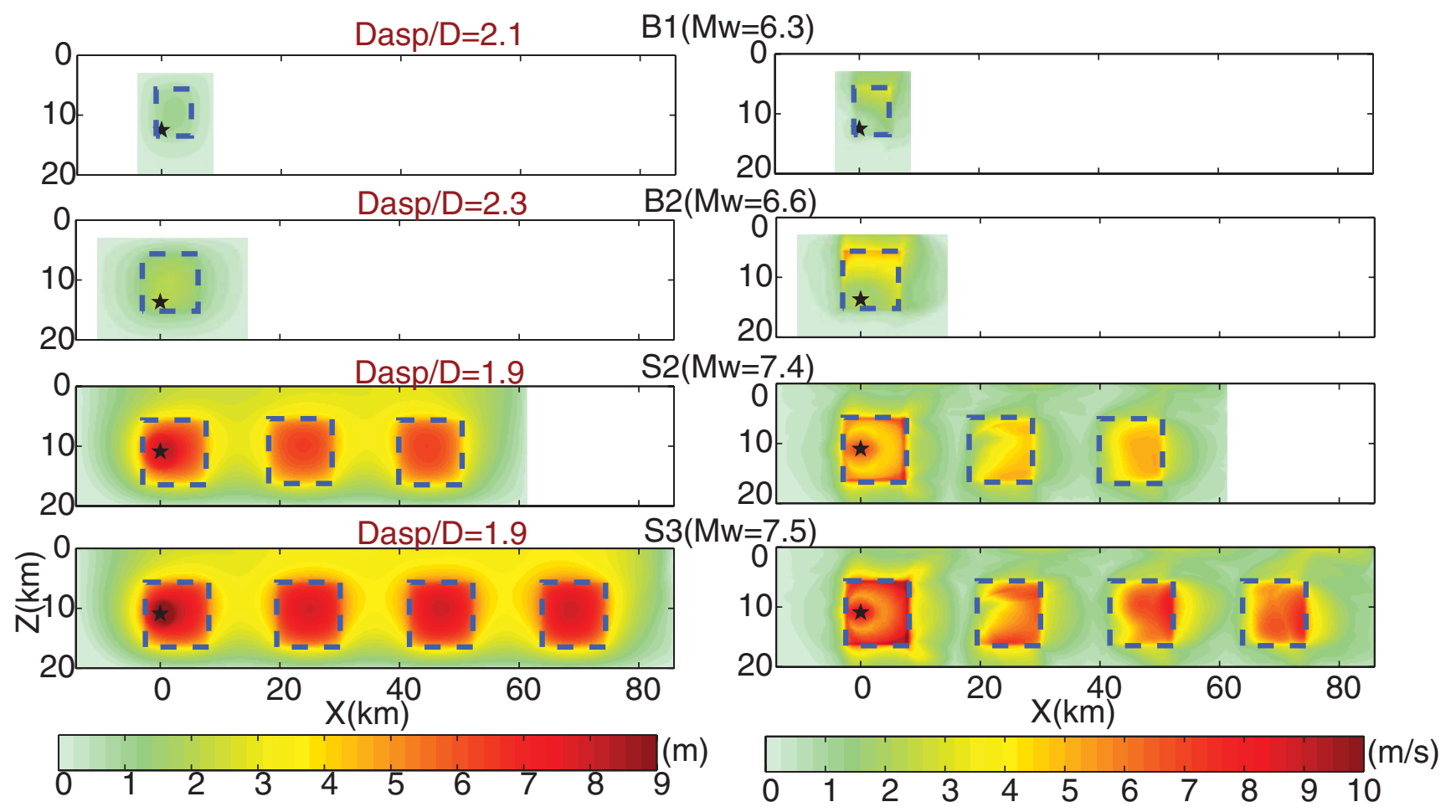

Figure 10. Final slip (left) and peak slip velocity (right) from the 3D spontaneous dynamic-rupture simulation of the buried (B models) and surface-rupturing (S models) earthquakes. The dashed line represents the asperities and the star the hypocenter location.

parameters by identifying the parameter sets that give results that conform, in a statistical sense, to key empirical observations from past earthquakes. Here we have followed this latter general strategy, in the context of a two-parameter slip-weakening friction model and a highly simplified asperity model for stress state. The key empirical constraints are (1) the asperity area and slip-ratio values that characterize moderate to large earthquakes (as interpreted by Somerville et al., 1999, from kinematic rupture inversions), and (2) the Irikura et al. (2004) empirical scaling relation (for seismic moment versus area).
There is of course substantial uncertainty in the resulting inferences of the dynamic parameters, as well as a very high degree of nonuniqueness, exacerbated by the requirement to select very simple parameterizations. Future efforts in this direction will have to consider much more complete parameterizations of the rupture physics; we have already mentioned stable sliding and/or distributed inelastic shearing beneath the seismic zone as a possible alternative (or additional) factor to explain the moment-area scaling, for example. Additional observational constraints should be incorporated as well. For example, we treated fracture energy as a free para-

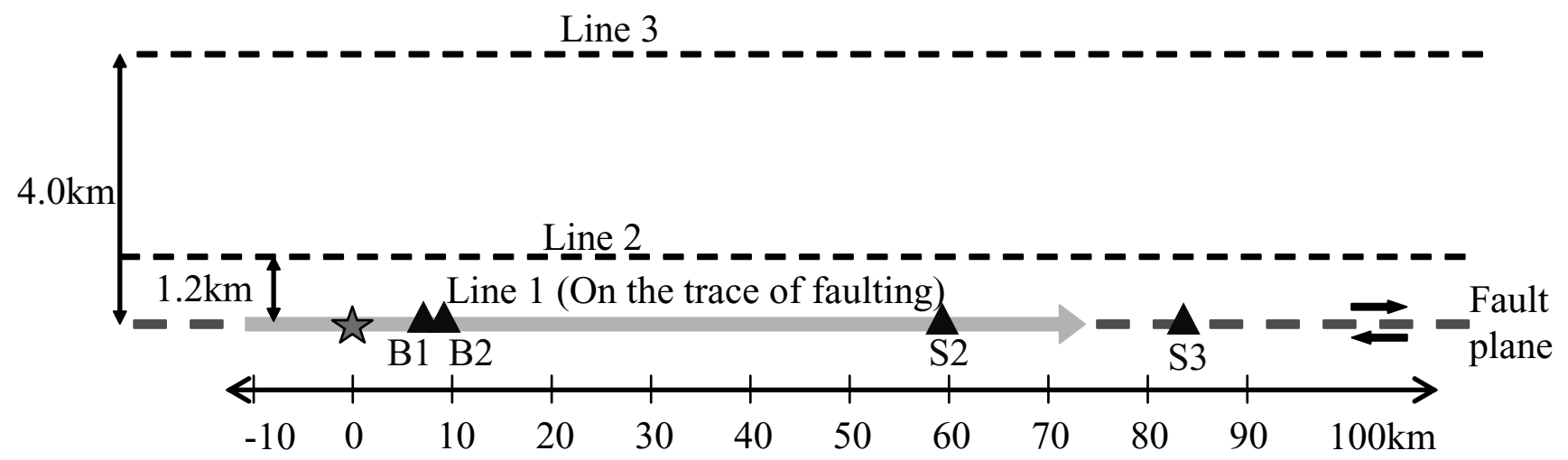

Figure 11. Location of receiver for ground-motion simulation on the free surface. Along the lines 1,2 , and 3 , peak velocity ground motions are saved. The triangles specify location of receivers for the velocity waveform, respectively, for each fault model (B and S models). The star is the projection of the hypocenter for all the fault models, where the origin of the axis along the strike of the fault is also located. 

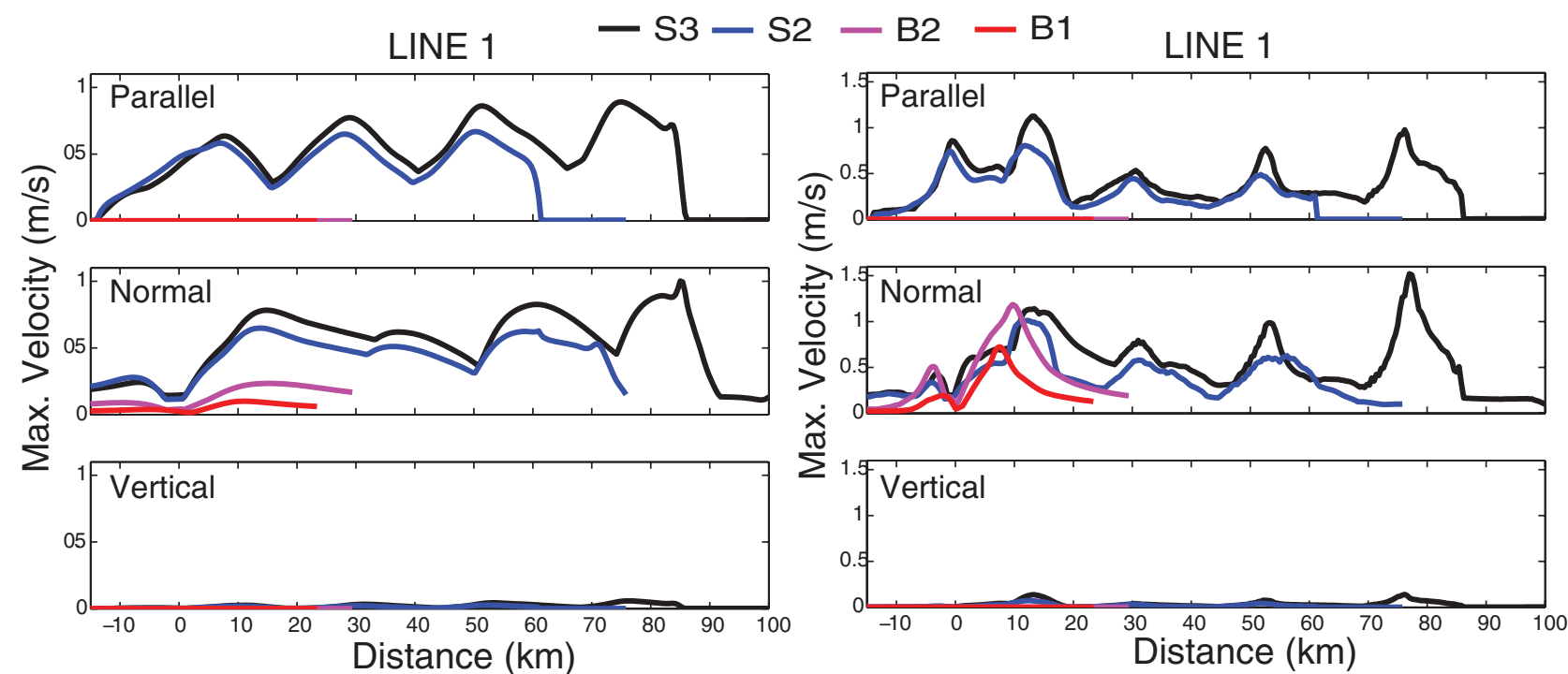

LINE 2

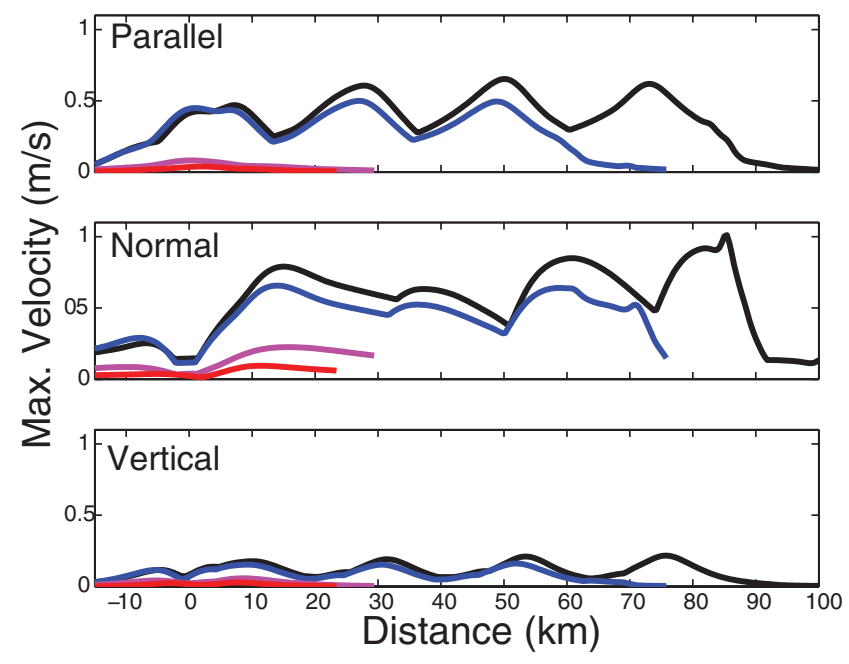

LINE 2

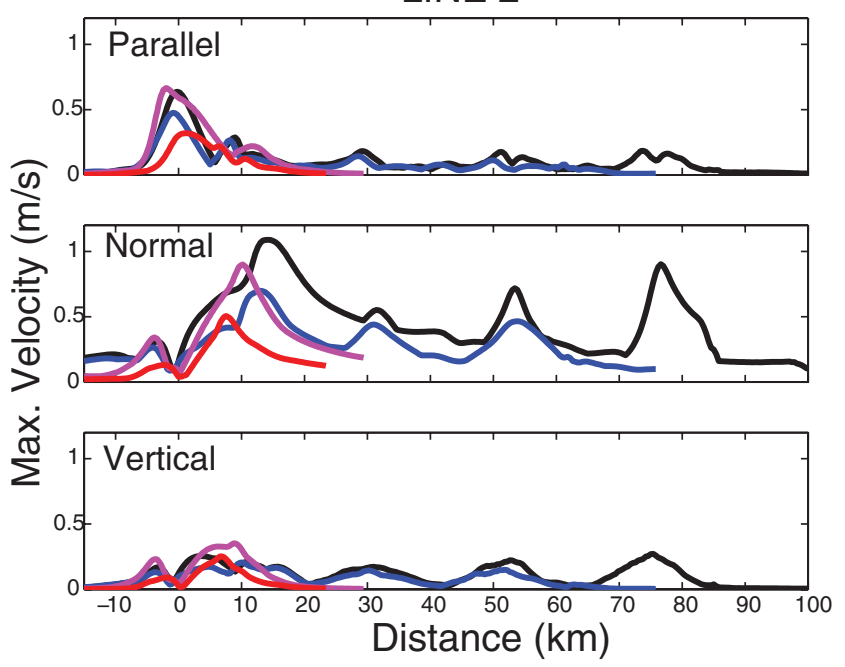

LINE 3
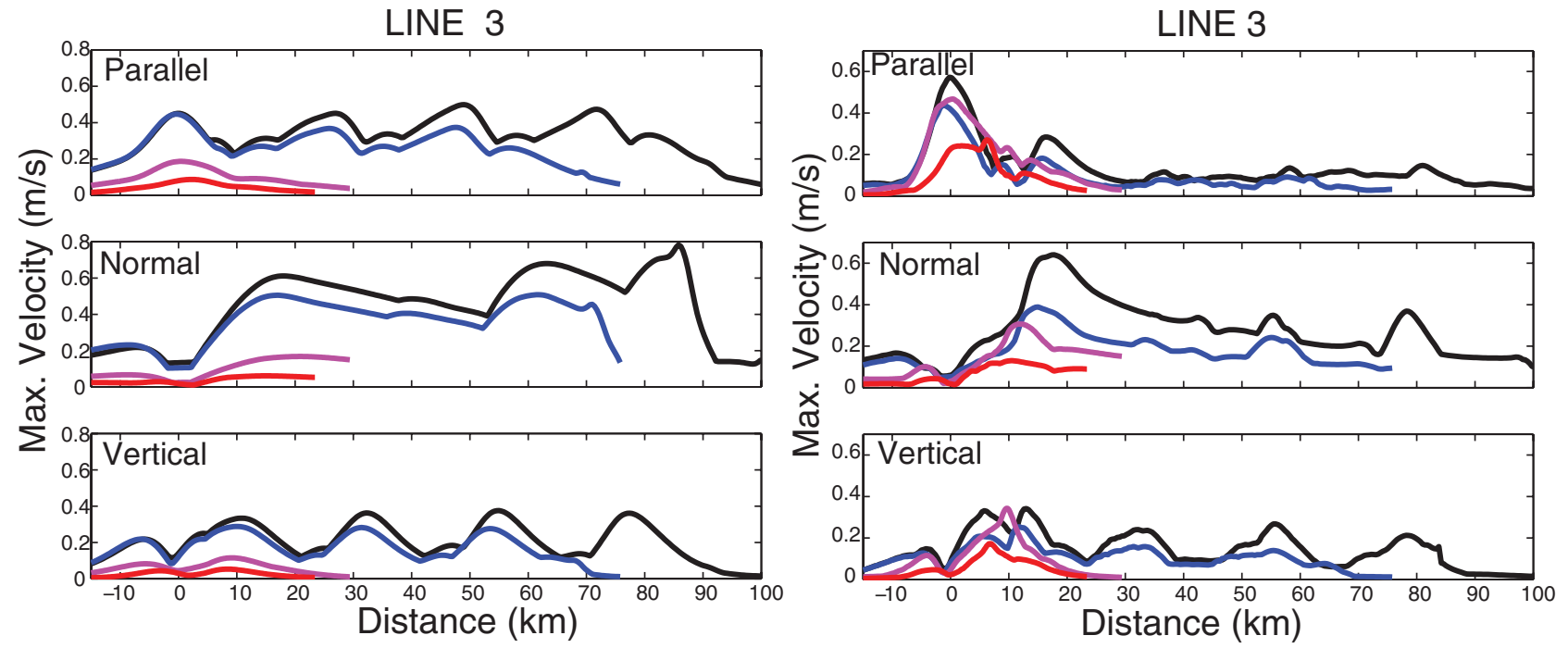

Figure 12. Parallel, normal, and vertical component of the peak velocity ground motion along the line 1 (upper), line 2 (middle), and line 3 (bottom) as specified in Figure 10, from the 3D spontaneous dynamic rupture simulation of the buried (B models) and surface-rupturing (S models) earthquakes. The left column and right column correspond, respectively, to low-pass filtered and high-pass filtered velocity wave forms, with cutoff frequency at $1 \mathrm{~Hz}$. 

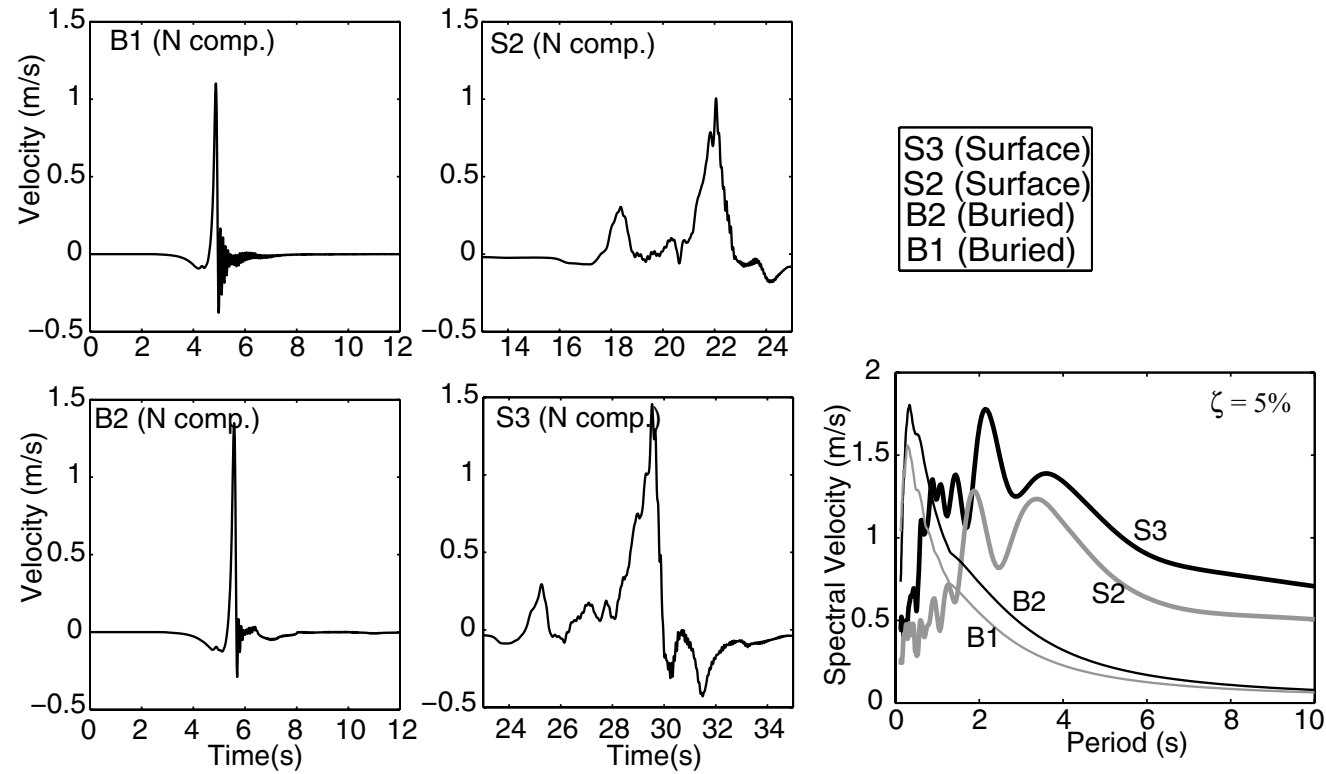

Figure 13. Time-history (left) and response spectral (right) of the normal component of the velocity ground motion located at receivers as specified in Figure 11, from the 3D spontaneous dynamic rupture simulation of the buried (B models) and surface-rupturing (S models) earthquakes.

meter in our explorations of buried versus surface-rupturing dynamics, and it would be very desirable to obtain independent empirical constraints.

Within the context of our parameterization, we find a significant difference in the stress-drop distribution between our buried-rupture models, which would represent small- to moderate-magnitude events, and surface-rupturing models, which would represent mainly large earthquakes rupturing the full seismogenic thickness. It is quite possible that a more realistic friction model with, for example, strong velocity dependence might be able to reproduce the asperity area and slip-ratio constraints without requiring the negative stressdrop areas, and this should be explored in future work incorporating more general friction laws. Alternatively, the large areas of apparent negative stress drop surrounding the asperities may be real, perhaps indicative of enhanced energy absorption mechanisms acting preferentially in large events, or preferentially at shallow depth (e.g., friction transitional between velocity weakening and velocity strengthening or offfault rupture-induced damage).

Again, within the context of our parameterization, the largest values of stress drop on the asperity of surfacerupturing earthquakes also provide us insight on the occurrence of large earthquakes. Because of the large amount of negative stress drop surrounding the asperities, large values of stress drop in the asperities appear to be necessary to allow rupture to progress until it becomes a large earthquake, as seen in the spontaneous dynamic-rupture simulations (Fig. 9). In addition, the dynamic models that match the empirical source-scaling model suggest that the average stress drop for the buried earthquakes is independent of earthquakes size, indicating that this type of earthquake follows self-similar scaling. On the contrary, large earthquakes characteristically suggest that the stress drop scales with the earthquake size, indicating that this type of earthquake breaks the self-similarity.

The fracture energy turns out to be the key parameter in our efforts to suggest an explanation for the proposed differences in frequency content between small buried earthquakes and large surface-rupturing earthquakes (Somerville, 2003). In numerical experiments, we found that an elevated value of fracture energy reduces high-frequency excitation (above about $1 \mathrm{~Hz}$ ), relative to simulations done with low fracture energy. The resulting shift in spectral content between the high and low fracture energy simulations is qualitatively consistent with the Somerville et al. empirical comparison of surface-rupturing earthquakes versus buried ruptures. The contrast in frequency content between the two types of events was enhanced in our simulations by the relatively strong upward directivity in the low fracture energy, single-asperity buried events, and the weakened high-frequency directivity in the surface-rupturing events. The latter was due in part to our assumption of shallower hypocentral depth for the surface-rupturing events, and perhaps in part to the incoherence of the rupture front that developed through its interaction with multiple, isolated asperities in a negative stressdrop background.

The importance of the fracture energy as a free parameter in our modeling points out the importance of obtaining independent empirical constraints on this parameter (or, more generally, of employing more realistic physical assumptions in which energy dissipation is not treated simply as a scale-invariant material property). The partial explanation we have proposed for observed spectral differences in 
ground motion between smaller, buried events and large, surface-rupturing events depends upon there being a systematic difference in fracture energy between the two event classes. This may be at least plausible, as several recent observational studies have suggested a relationship between fracture energy and earthquake size (e.g., Ide and Takeo, 1997; Tinti et al., 2005; Mai et al., 2006). The fracture energy may be a macroscale representation of bulk microfracturing, which would be expected to scale with event size (e.g., Yamashita, 2000; Poliakov et al., 2002; Dalguer et al., 2003a,b; Andrews, 2005; Rice et al., 2005). There is also some independent evidence suggestive of higher fracture energy in shallow rupture (e.g., Ide and Takeo, 1997). Rateand state-dependent friction models also predict enhanced dissipation for very shallow rupture, where velocity-strengthening friction is expected to pertain (e.g., Marone and Scholz, 1988). Enhanced energy absorption zones due to off-fault damage are possible characteristics of larger faults. A damage zone can be accumulated during the lifetime of a fault, either as the result of dynamic stress change induced by rupture during an earthquake (e.g., Dalguer et al., 2003a,b; Andrews, 2005) or from quasi-static deformation during the life of a shear fault (e.g., Vermilye and Scholz, 1998).

In this work we used a highly simplified parameterization of the rupture process, calibrating the parameters separately for different types and sizes of events so as to conform to empirical scaling relations. This approach provided some useful insights into the origin of ground-motion differences between surface-rupturing and buried earthquakes, but is unsatisfying from a physical perspective. It is a step in a longerterm program to model more realistic initial stress conditions and a more complete thermo-mechanical description of the rupture process, and to simulate large suites of events without predetermined constraints on individual event sizes. The ground-motion scaling laws that emerge naturally from such simulation suites may then be compared directly with statistics from past earthquakes to identify acceptable ranges of the model parameters. It is our hope that this approach will contribute to an improved capability for the prediction of ground motion from future earthquakes.

\section{Acknowledgments}

We would like to thank the two reviewers of the article, Joe Andrews and Benchun Duan, and the associate editor David D. Oglesby for constructive comments and very helpful reviews that led to improvements in the manuscript. This work was partially supported by (1) the Study on Development of Simulation System and its Application for Catastrophic Earthquake and Tsunami Disaster Response in Mega-Cities Facing the Pacific in Special Project for Earthquake Disaster Mitigation in Urban Areas in RR2002, by the Ministry of Education, Science, Sports, and Culture of Japan; and (2) by the National Science Foundation (NSF), under Grants Number ATM-0325033 and Number EAR-0623704, by the Southern California Earthquake Center (SCEC). The SCEC is funded by NSF Cooperative Agreement EAR-0106924 and U.S. Geological Survey Cooperative Agreement 07HQAG0008. The SCEC contribution number for this article is 1104 .

\section{References}

Abercrombie, R. E. (1995). Earthquake source scaling relationship from -1 to $5 \mathrm{M}_{\mathrm{L}}$ using seismograms recorded at $2.5 \mathrm{~km}$ depth, J. Geophys. Res. 100, 24,015-24,036.

Abercrombie, R. E., and J. R. Rice (2005). Can observations of earthquake scaling constrain slip weakening?, Geophys. J. Int. 162, 406-424.

Andrews, D. J. (1976). Rupture velocity of plane-strain shear cracks, J. Geophys. Res. 81, 5679-5687.

Andrews, D. J. (2005). Rupture dynamics with energy loss outside the slip zone, J. Geophys. Res. 110, B01307, doi 10.1029/2004JB003191.

Asano, K., T. Iwata, and K. Irikura (2005). Estimation of source rupture process and strong ground motion simulation of the 2002 Denali, Alaska, earthquake, Bull. Seismol. Soc. Am. 95, 1701-1715.

Bouchon, M. (1997). The state of stress on some faults of the San Andreas system as inferred from nearfield strong motion data, J. Geophys. Res. 102, 11,731-11,744.

Bouchon, M., H. Sekiguchi, K. Irikura, and T. Iwata (1998). Some characteristics of the stress field of the 1995 Hyongo-ken Nanbu (Kobe) earthquake, J. Geophys. Res. 103, 24,271-24,282.

Dalguer, L. A., and S. M. Day (2006). Comparison of fault representation methods in finite difference simulations of dynamic rupture, Bull. Seismol. Soc. Am. 96, 1764-1778.

Dalguer, L. A., and S. M. Day (2007). Staggered-grid split-nodes method for spontaneous rupture simulation, J. Geophys. Res. 112, B02302, doi 10.1029/2006JB004467.

Dalguer, L. A., S. M. Day, K. Olsen, and Y. Cui (2006). Implementation of the staggered-grid split-node method in a MPI finite difference code for large scale models of spontaneous dynamic rupture simulation, in 2006 SCEC Annual Meeting Proceedings and Abstracts, Vol. 16, Southern California Earthquake Center, Los Angeles.

Dalguer, L. A, K. Irikura, and J. Riera (2003a). Generation of new cracks accompanied by the dynamic shear rupture propagation of the 2000 Tottori (Japan) earthquake, Bull. Seismol. Soc. Am. 93, 2236-2252.

Dalguer, L. A., K. Irikura, and J. Riera (2003b). Simulation of tensile crack generation by 3D dynamic shear rupture propagation during an earthquake, J. Geophys. Res. 108, no. B3, 2144, doi 10.1029/ 2001JB001738.

Dalguer, L. A., K. Irikura, J. Riera, and H. C. Chiu (2001). The importance of the dynamic source effects on strong ground motion during the 1999 Chi-Chi (Taiwan) earthquake: brief interpretation of the damage distribution on buildings, Bull. Seismol. Soc. Am. 95, 1112-1127.

Dalguer, L. A., K. Irikura, W. Zhang, and J. Riera (2002). Distribution of dynamic and static stress changes during 2000 Tottori (Japan) earthquake: brief interpretation of the earthquake sequences; foreshocks, main shock and aftershocks, Geophys. Res. Lett. 29, no. 16, 1758, doi 10.1029/2001GL014333.

Dalguer, L. A., H. Miyake, and K. Irikura (2004). Paper No. 3286, Characterization of dynamic asperity source models for simulating strong ground motion, in Proceedings of the 13th World Conference on Earthquake Engineering (13WCEE), Vancouver, B.C., Canada, 1-6 August 2004.

Das, S., and K. Aki (1977). Fault planes with barriers: a versatile earthquake model, J. Geophys. Res. 82, 5648-5670.

Day, S. M. (1982a). Three-dimensional finite difference simulation of fault dynamics: rectangular faults with fixed rupture velocity, Bull. Seismol. Soc. Am. 72, 705-727.

Day, S. M. (1982b). Three-dimensional simulation of spontaneous rupture: the effect of nonuniform prestress, Bull. Seismol. Soc. Am. 72, 18811902.

Day, S. M., S. H. Gonzalez, R. Anooshehpoor, and J. N. Brune (2008). Scale-model and numerical simulations of near-fault seismic directivity, Bull. Seismol. Soc. Am. 98, 1186-1206.

Day, S. M., G. Yu, and D. J. Wald (1998). Dynamic stress changes during earthquake rupture, Bull. Seismol. Soc. Am. 88, 512-522. 
Guatteri, M., and P. Spudich (2000). What can strong-motion data tell us about slip-weakening fault-friction laws?, Bull. Seismol. Soc. Am. 90, 98-116.

Hanks, T. C. (1977). Earthquake stress drops, ambient tectonic stresses and stresses that drive plate motions, Pure Appl. Geophys. 115, 441-458.

Hanks, T. C., and W. H. Bakun (2002). A bilinear source-scaling model for M-log A observations of continental earthquakes, Bull. Seismol. Soc. Am. 92, 1841-1846.

Ide, S. (2002). Estimation of radiated energy of finite-source earthquake models, Bull. Seismol. Soc. Am. 92, 2994-3005.

Ide, S., and M. Takeo (1997). Determination of constitutive relations of fault slip based on seismic waves analysis, J. Geophys. Res. 102, 27,37927,391 .

Irikura, K., and H. Miyake (2001). Prediction of strong ground motions for scenario earthquakes, J. Geograph. 110, 849-875 (in Japanese with English abstract).

Irikura, K., H. Miyake, T. Iwata, K. Kamae, H. Kawabe, and L. A. Dalguer (2004). Paper No. 1371, Recipe for predicting strong ground motion from future large earthquake, in Proceedings of the 13th World Conference on Earthquake Engineering (13WCEE), Vancouver, B. C., Canada, 1-6 August 2004.

Kagawa, T., K. Irikura, and P. Somerville (2004). Differences in ground motion and fault rupture process between surface and buried rupture earthquakes, Earth Planets Space 56, 3-14.

Kanamori, H., and D. Anderson (1975). Theoretical basis of some empirical relations in seismology, Bull. Seismol. Soc. Am. 65, 1073-1095.

Kanamori, H., J. Mori, E. Hauksson, T. H. Heaton, L. K. Hutton, and L. M. Jones (1993). Determination of earthquake energy release and $\mathrm{M}_{\mathrm{L}}$ using TERRAscope, Bull. Seismol. Soc. Am. 83, 330-346.

Mai, P. M., and G. C. Beroza (2000). Source-scaling properties from finitefault rupture models, Bull. Seismol. Soc. Am. 90, 604-615.

Mai, P. M., P. Somerville, A. Pitarka, L. Dalguer, S. G. Song, G. Beroza, H. Miyake, and K. Irikura (2006). On scaling of fracture energy and stress drop in dynamic rupture models: consequences for near-source ground motions, in Earthquakes: Radiated Energy and the Physics of Faulting, R. Abercrombie, A. McGarr, H. Kanamori and G. Di Toro (Editors), American Geophysical Monograph 170, 283-293.

Mai, P. M., P. Spudich, and J. Boatwright (2005). Hypocenter locations in finite-source rupture models, Bull. Seismol. Soc. Am. 95, 965-980.

Marone, C., and C. Scholz (1988). The depth of seismic faulting and the upper transition from stable to unstable slip regimes, Geophys. Res. Lett. 15, 621-624.

Mikumo, T., K. B. Olsen, E. Fukuyama, and Y. Yagi (2003). Stress-breakdown time and slip-weakening distance inferred from slip-velocity functions on earthquake faults, Bull. Seismol. Soc. Am. 93, 264-282.

Miyake, H., T. Iwata, and K. Irikura (2003). Source characterization for broadband ground-motion simulation: kinematic heterogeneous source model and strong motion generation area, Bull. Seismol. Soc. Am. 93, 2531-2545.

Miyakoshi, K. (2002). Source characterization for heterogeneous source model, Chikyu Mon. Extra 37, 42-47 (in Japanese).

Oglesby, D. D., R. J. Archuleta, and S. B. Nielsen (1998). Earthquakes on dipping faults: the effects of broken symmetry, Science 280, 10551059.

Olsen, K. B., S. M. Day, J. B. Minster, Y. Cui, A. Chourasia, M. Faerman, R. Moore, P. Maechling, and T. Jordan (2006). Strong shaking in Los Angeles expected from southern San Andreas earthquake, Geophys. Res. Lett. 33, L07305, doi 10.1029/2005GRL025472.

Olsen, K. B., S. M. Day, J. B. Minster, Y. Cui, A. Chourasia, D. Okaya, P. Maechling, and T. Jordan (2008). TeraShake2: spontaneous rupture simulation of $M_{\mathrm{w}} 7.7$ earthquakes on the southern San Andreas fault, Bull. Seismol. Soc. Am. 98, 1162-1185.

Olsen, K. B., R. Madariaga, and R. Archuleta (1997). Three dimensional dynamic simulation of the 1992 Landers earthquake, Science 278, 834-838.
Peyrat, S., K. Olsen, and R. Madariaga (2001). Dynamic modeling of the 1992 Landers earthquake, J. Geophys. Res. 106, 26,467-26,482.

Poliakov, A. N. B., R. Dmowska, and J. R. Rice (2002). Dynamic shear rupture interactions with fault bends and off-axis secondary faulting, J. Geophys. Res. 107, no. B11, 2295, doi 10.1029/2001JB000572.

Pulido, N., and K. Irikura (2000). Estimation of dynamic rupture parameters from the radiated seismic energy and apparent stress, Geophys. Res. Lett. 27, 3945-3948.

Rice, J. R., C. G. Sammis, and R. Parsons (2005). Off-fault secondary failure induced by a dynamic slip pulse, Bull. Seismol. Soc. Am. 95, 109-134.

Scholz, C. H. (1982). Scaling laws for large earthquakes: consequences for physical models, Bull. Seismol. Soc. Am. 72, 1-14.

Scholz, C. H. (2002). The Mechanics of Earthquakes and Faulting Cambridge U Press, New York.

Sekiguchi, H., and T. Iwata (2002). Rupture process of the 1999 Kocaeli, Turkey, earthquake estimated from strong-motion waveforms, Bull. Seismol. Soc. Am. 92, 300-311.

Somerville, P. G. (2003). Magnitude scaling of the near fault rupture directivity pulse, Phys. Earth Planet. Interiors 137, 201-212.

Somerville, P., K. Irikura, R. Graves, S. Sawada, D. Wald, N. Abrahamson, Y. Iwasaki, T. Kagawa, N. Smith, and A. Kowada (1999). Characterizing crustal earthquake slip models for the prediction of strong ground motion, Seism. Res. Lett. 70, 59-80.

Tinti, E., P. Spudich, and M. Cocco (2005). Earthquake fracture energy inferred from kinematic rupture models on extended faults, J. Geophys. Res. 110, B12303, doi 10.1029/2005JB003644.

Vermilye, J. M., and C. H. Scholz (1998). The process zone: a microstructural view of fault growth, J. Geophys. Res. 103, 12,223-12,237.

Wald, D. J., and T. H. Heaton (1994). Spatial and temporal distribution of slip for the 1992 Landers, California, earthquake, Bull. Seismol. Soc. Am. 84, 668-691.

Wells, D. L., and K. L. Coppersmith (1994). New empirical relationships among magnitude, rupture width, rupture area, and surface displacement, Bull. Seismol. Soc. Am. 84, 974-1002.

Yamashita, T. (2000). Generation of microcracks by dynamic shear rupture and its effects on rupture growth and elastic wave radiation, Geophys. J. Int. 143, 395-406.

Zhang, W. B., T. Iwata, K. Irikura, H. Sekiguchi, and M. Bouchon (2003). Heterogeneous distribution of the dynamic source parameters of the 1999 Chi-Chi, Taiwan, earthquake, J. Geophys. Res. 108, 2232, doi 10.1029/2002JB001889.

Department of Geological Sciences

San Diego State University

5500 Campanile Dr.

San Diego, California 92182

ldalguer@moho.sdsu.edu

day@moho.sdsu.edu

(L.A.D., S.M.D.)

Earthquake Research Institute

University of Tokyo

1-1-1 Yayoi, Bunkyo-ku

Tokyo 113-0032, Japan

hiroe@eri.u-tokyo.ac.jp

(H.M.)

Disaster Prevention Research Center

Aichi Institute of Technology

1247 Yachigusa, Yakusa

Toyota, Aichi 470-0392, Japan

irikura@geor.or.jp

(K.I.)

Manuscript received 24 May 2007 